\title{
Improving the Outcome of Acute Pancreatitis
}

\author{
Marco J. Bruno on behalf of the Dutch Pancreatitis Study Group \\ Department of Gastroenterology and Hepatology, Erasmus Medical Center, University Medical Center Rotterdam, \\ Rotterdam, The Netherlands
}

\section{Key Words}

Acute pancreatitis - Acute necrotizing pancreatitis .

Biliary pancreatitis

\begin{abstract}
Acute pancreatitis (AP) is the most common indication for hospital admission and its incidence is rising. It has a variable prognosis, which is mainly dependent upon the development of persistent organ failure and infected necrotizing pancreatitis. In the past few years, based on large-scale multicenter randomized trials, some novel insights regarding clinical management have emerged. In patients with infected pancreatic necrosis, a step-up approach of percutaneous catheter drainage followed by necrosectomy only when the patient does not improve, reduces new-onset organ failure and prevents the need for necrosectomy in about a third of patients. A randomized pilot study comparing surgical to endoscopic necrosectomy in patients with infected necrotizing pancreatitis showed a striking reduction of the pro-inflammatory response following endoscopic necrosectomy. These promising results have recently been tested in a large multicenter randomized trial whose results are eagerly awaited. Contrary to earlier data from uncontrolled studies, a large multicenter randomized trial comparing early (within $24 \mathrm{~h}$ ) nasoenteric tube feeding compared with an oral diet after $72 \mathrm{~h}$, did not show that early nasoenteric tube feeding was superior in reducing the rate of infection or death in patients with AP at high risk for complications. Although early
\end{abstract}

\begin{tabular}{ll}
\hline KARGER & $\begin{array}{l}\text { ( ) 2016 The Author(s) } \\
\text { Published by S. Karger AG, Basel } \\
\text { 0257-2753/16/0345-0540\$39.50/0 }\end{array}$ \\
E-Mail karger@karger.com & $\begin{array}{l}\text { This article is licensed under the Creative Commons Attribution- } \\
\text { www.karger.com/ddi }\end{array}$ \\
& $\begin{array}{l}\text { NonCommercial-NoDerivatives 4.0 International License (CC BY- } \\
\text { NC-ND) (http://www.karger.com/Services/OpenAccessLicense). } \\
\text { Usage and distribution for commercial purposes as well as any dis- } \\
\text { tribution of modified material requires written permission. }\end{array}$
\end{tabular}

Professor Marco J. Bruno, MD, PhD

Department of Gastroenterology and Hepatology

Erasmus Medical Center, University Medical Center Rotterdam

's Gravendijkwal 230, NL-3015 CE Rotterdam (The Netherlands)

E-Mail m.bruno@erasmusmc.nl

ERCP does not have a role in the treatment of predicted mild pancreatitis, except in the case of concomitant cholangitis, it may ameliorate the disease course in patients with predicted severe pancreatitis. Currently, a large-scale randomized study is underway and results are expected in 2017.

(c) 2016 The Author(s)

Published by S. Karger AG, Basel

\section{Introduction}

Acute pancreatitis (AP) is the most common gastrointestinal condition requiring acute hospital admission [1]. In 2009, more than 270,000 patients were diagnosed with AP in the United States and costs are estimated to exceed 2.5 billion dollars every year. Eighty percent of patients develop edematous pancreatitis with severe abdominal pain, which usually subsides within days without development of further complications. Around 20\% of patients, however, develop necrotizing pancreatitis of which about a third gets infected with mortality rates up to $30 \%[2,3]$. Unfortunately, no drug therapy is available to ameliorate the disease course, in particular for those who develop a systemic inflammatory response syndrome (SIRS). Prophylactic administration of intravenous antibiotics does not prevent infected pancreatic necrosis. Antibiotics are only indicated in case of a proven infection or in case of a very strong clinical suspicion of either infected necrosis or cholangitis. In the latter case, biliary drainage is mandatory. Optimal feeding has always been regarded as an im- 
portant means to improve the outcome in this potentially lethal disease. Starting early enteral feeding as soon as possible was thought to be important, but until recently no scientific study was available to support this. Although it is generally accepted that early ERCP has no role in patients with predicted mild biliary pancreatitis, unless there is concomitant cholangitis, there is an ongoing discussion whether in patients with a predicted severe disease course early de-obstruction of the ampulla of Vater and biliary sphincterotomy, with removal of bile duct stones and sludge, is beneficial to prevent complications.

\section{Treatment of Infected Pancreatic Necrosis}

Approximately, 20\% of pancreatitis patients develop necrosis of the pancreatic parenchyma and/or extra-pancreatic fat tissue. Necrosis can been visualized on CT-scan as noncontrast-enhancing regions in and around the pancreas that consist of solid tissue and fluid. As long as these collections remain sterile and asymptomatic, that is, with no pain, gastric outlet obstruction or biliary obstruction, treatment is generally conservative. Between 4 and 6 weeks after disease onset, (peri)pancreatic necrosis may either disappear by resorption or perforation to the digestive tract or become liquefied and a large encapsulated fluid collection develops. In about a third of patients, pancreatic necrosis becomes infected. This is associated with a mortality rate of approximately $30 \%$ and is virtually always an indication for invasive treatment. Without intervention, mortality approaches 100\% [3-6]. In the earlier days, surgical necrosectomy was performed through a laparotomy, but this carried a very high morbidity rate, as it constitutes a major 'hit' to an already critically ill patient. This pushed the practice of postponing intervention in infected pancreatic necrosis until the development of walled-off necrosis $[3,7,8]$.

With this concept in mind of minimizing surgical trauma as much as possible, the PANTER trial was initiated within the framework of the Dutch Pancreatitis Study Group [9]. In this multicenter randomized study, 88 patients with necrotizing pancreatitis and with suspected or confirmed infected necrotic tissue were randomized to undergo primary open necrosectomy or a step-up approach treatment. The step-up approach consisted of percutaneous drainage followed, if necessary, by minimally invasive retroperitoneal necrosectomy. The primary end point, a composite of major complications (new-onset multiple-organ failure or multiple systemic complications, perforation of a visceral organ or enterocutaneous fistula, or bleeding) or death, occurred in $69 \%$

Improving the Outcome of AP of patients assigned to open necrosectomy and in $40 \%$ of patients assigned to the step-up approach (risk ratio with the step-up approach, $0.57 ; 95 \%$ CI $0.38-0.87 ; \mathrm{p}=0.006$ ). Importantly, $35 \%$ of the patients assigned to the step-up approach did not require surgical necrosectomy and were treated with percutaneous drainage only. New-onset multiple-organ failure occurred significantly less often in patients assigned to the step-up approach (12\%) than in those assigned to open necrosectomy (40\%). The rate of death did not differ significantly between groups.

After publication of this landmark study pertaining to the management of infected pancreatic necrosis, current guidelines recommend a step-up approach of delayed catheter drainage until the (peri)pancreatic collection has reached the stage of walled-off necrosis, a process that usually takes 4-6 weeks, at which time catheter drainage is followed by necrosectomy when needed.

In order to decrease surgical trauma, video-assisted retroperitoneal debridement was developed. In the latter case, the percutaneous catheter tract is surgically explored by minimal invasive means using a video endoscope, allowing identification and removal of large chunks of necrotic materials [8]. Moreover, endoscopic ultrasonography-guided drainage and necrosectomy techniques have been developed [10]. By means of this technique, the infected collection is identified using a linear ultrasonography endoscope either from the stomach or from the duodenum, and punctured by using a needle or cautery device after which the collection is drained with pigtail plastic stents or a metallic endoprosthesis. In case of ongoing infection and clinical deterioration of the patient, the same cystogastrostomy tract can be dilated up to 20 $\mathrm{mm}$ and used as a port d' entre to enter the collection with a regular forward-viewing endoscope, allowing endoscopic removal of necrotic tissue.

Bakker et al. [11] performed on behalf of the Dutch Pancreatitis Study Group a randomized controlled assessor-blinded pilot study (PINGUIN study) in which patients with infected necrotizing pancreatitis were randomized to endoscopic transgastric or surgical necrosectomy. Endoscopic necrosectomy consisted of transgastric puncture, balloon dilatation, retroperitoneal drainage, and necrosectomy. Surgical necrosectomy consisted of video-assisted retroperitoneal debridement or, if not feasible, laparotomy. The premise of this study was that surgical necrosectomy induces a proinflammatory response and is associated with a high complication rate, whereas endoscopic transgastric necrosectomy, a form of natural orifice transluminal endoscopic surgery, may reduce the proinflammatory response and thus reduce complications. The 
primary end point in this pilot study was the postprocedural proinflammatory response as measured by serum interleukin 6 (IL-6) levels. Secondary clinical end points included a predefined composite end point of major complications (new onset multiple organ failure, intra-abdominal bleeding, enterocutaneous fistula, or pancreatic fistula) or death. In total, 22 patients were randomized, 2 of whom did not undergo necrosectomy following percutaneous catheter drainage and therefore could not be analyzed for the primary end point. Endoscopic transgastric necrosectomy significantly reduced the postprocedural IL-6 levels compared with surgical necrosectomy. Twenty-four hours after intervention, IL-6 levels in patient undergoing surgical necrosectomy rose, while in patients undergoing endoscopic necrosectomy, IL-6 levels decreased. This difference in IL- 6 levels between the 2 intervention groups persisted 1 week after treatment. Although the study was powered for Il-6 levels as a proxy for disease severity, and was not adequately powered to definitely answer the secondary endpoints, the differences were striking. The composite endpoint of major complications and death occurred in $20 \%$ of patients treated by means of endoscopy compared to $80 \%$ in patients treated with surgery. This difference was statistically significant and obviously carries an important clinical relevance. The same pattern emerged for new onset organ failure; $0 \%$ after endoscopic treatment vs. $50 \%$ after surgical treatment.

The remarkable outcome of this pilot study formed the basis of the design of a large-scale, adequately powered, randomized, controlled, parallel-group superiority multicenter trial (TENSION trial) to answer the question whether in patients with (suspected) infected necrotizing pancreatitis with an indication for intervention and in whom both treatment modalities are deemed possible, endoscopic transluminal step-up treatment is superior to a surgical step-up approach. Patient inclusion of this study has been completed and the data are currently being analyzed. Over a 4-year time period, 98 patients have been enrolled from 24 hospitals of the Dutch Pancreatitis Study Group. The primary endpoint is a composite of death and major complications within 6 months following randomization. Secondary endpoints include complications such as pancreaticocutaneous fistula, exocrine or endocrine pancreatic insufficiency, need for additional radiological, endoscopic or surgical intervention, the need for necrosectomy after drainage, the number of (re-) interventions, quality of life, and total direct and indirect costs. Soon, the TENSION trial will provide a conclusive answer whether an endoscopic step-up approach reduces the combined primary endpoint of death and major com- plications, as well as hospital stay and related costs compared with a surgical step-up approach in patients with infected necrotizing pancreatitis.

Since the step-up approach is now considered standard practice [2] and the results of the TENSION trial will soon reveal which strategy is to be preferred, the question of optimal timing of drainage has become the next focal point of discussion both in terms of safety and cost-effectiveness. Current literature shows that $35-64 \%$ of patients with INP can be treated with delayed catheter drainage, without the need for invasive necrosectomy $[9,13]$. In a recent international survey, although not evidence based, $45 \%$ of expert pancreatologists proclaimed that they immediately proceed with catheter drainage once infected pancreatic necrosis has been established [12]. Indeed, various case series suggest that encapsulation is not a 'sine qua non' for catheter drainage to be successful [13].

Therefore, optimal timing of drainage is the next research question to be tackled by the Dutch Pancreatitis Study Group. For this, the POINTER study has been designed of which patient inclusion has already started. This study investigates whether a strategy of early diagnosis of infected pancreatic necrosis in combination with immediate catheter drainage is more beneficial with regard to clinical outcome and cost effectiveness than the current standard of postponed catheter drainage until walled-off necrosis has developed. With the current strategy of delayed intervention, patients with infected pancreatic necrosis are clinically observed for long periods of time awaiting resolution of necrosis. Consequently, the utilization of health care resources is high with direct medical costs exceeding $€ 80,000(\$ 110,000)$ [9]. However, 35$64 \%$ of patients with infected pancreatic necrosis that are treated with postponed catheter drainage do not require necrosectomy $[9,13]$. If such a high percentage of patients respond so favorably to delayed catheter drainage, it is only logical to hypothesize that earlier catheter drainage may be even more beneficial in terms of preventing serious complications to occur including organ failure and sepsis and the need for necrosectomy.

With this new concept of very early drainage, the methodology of how to diagnose infected pancreatic necrosis needs to be re-evaluated. With the strategy of postponed drainage, the clinical features of either gas in the necrotic collection on cross-sectional imaging or ongoing organ failure for several weeks after the onset of AP and a failure to thrive, enabled a correct diagnosis of infection of the necrosis in $91 \%$ of patients [9]. However, with regard to setting the correct indication for very early drainage, it will prove impossible to distinguish between the SIRS and infected 
pancreatic necrosis on clinical grounds. In order to make a correct diagnosis in these very early stages, additional diagnostic procedures like fine needle aspiration (FNA) are required to confirm or exclude infection in the first 2 weeks after disease onset. In a recent study, infected pancreatic necrosis was confirmed by FNA in $86 \%$ of patients, which is equal to the diagnostic performance of clinical symptoms $(80 \%)$ or gas bubbles on CT-scan (94\%) [14].

\section{Feeding in Pancreatitis}

Feeding in AP has always been an area of major interest to prevent secondary infection of necrosis and improve patient outcome. It is hypothesized that infection of pancreatic necrosis is mediated by bacterial translocation from the gut, provoked by disturbed intestinal motility, bacterial overgrowth, and increased mucosal permeability [15-19]. Nasoenteric tube feeding is believed to stimulate intestinal motility, which may reduce bacterial overgrowth and preserve gut mucosal integrity through the stimulation of splanchnic blood flow [20,21]. A comprehensive meta-analysis involving 8 randomized trials with a total of 348 patients showed that nasoenteric tube feeding compared with total parenteral nutrition reduced the rate of infections and mortality among patients with severe pancreatitis [22]. A meta-analysis of randomized trials involving acutely ill patients, but no pancreatitis, showed a $22 \%$ reduction in the rate of major infections when nasoenteric tube feeding was started $\leq 36 \mathrm{~h}$ as compared with a later start [23]. In patients with AP, nonrandomized studies have shown that nasoenteric tube feeding started within $48 \mathrm{~h}$ after admission, as compared with a start after $48 \mathrm{~h}$, significantly reduced the rate of major infection and in some studies even reduced mortality [24-27]. Importantly, the use of an enteric feeding tube not only has presumed benefits. Many patients dislike having a feeding tube because it may cause substantial discomfort including throat pain and excessive gagging. Moreover, feeding tubes may dislodge due to gagging or become obstructed due to impacted feeding fluid necessitating frequent replacement of the tube. A more restricted use of enteral nutrition and a feeding tube only in those patients who really benefit from it, would result in substantial avoidance of discomfort and costs.

Recently, a large multicenter randomized controlled study from the Dutch Pancreatitis Study Group did not show that in patients with AP at high risk for complications, an early start of nasoenteric tube feeding is superior compared to the introduction of an oral diet after $72 \mathrm{~h}$ (with tube feeding only on-demand) [28]. There was no statistically significant difference with regard to the composite end point of major infection or death or for the secondary endpoints including development of necrotizing pancreatitis, infected pancreatic necrosis, bacteremia, CT severity index, ICU admission, and organ failure. With the oral diet and on-demand tube feeding strategy, only approximately one third of patients required a nasojejunal feeding tube. It is difficult to speculate on factors that explain the observed differences with previous trials and observational studies, which suggested an improved outcome after early nasoenteric tube feeding as compared with total parenteral nutrition, other than study design and methodology $[8,10-13]$. The timing of early nasoenteric tube feeding was similar to the timing mentioned in previous studies and similar criteria for enrolling patients at high risk for complications were used. One of the major issues with observational studies is that one cannot differentiate between cause and effect; for instance, less severely ill patients may have been fed earlier. This discussion on (early) feeding to ameliorate the disease course is not limited to patients with pancreatitis. In most current ICU guidelines, early enteral feeding is recommended, but the methodologic quality of the included trials has been criticized [29-31]. American and European nutritional societies recommend routine early nasoenteric tube feeding in all patients with severe pancreatitis [32-34]; guidelines from gastroenterologic and pancreatic societies, however, state that, regardless of disease severity, tube feeding is indicated when patients are predicted not to be able to tolerate an oral diet for up to 7 days $[35,36]$. Unfortunately, it takes several days after admission to make such assessment and by that time the window of opportunity for effective prevention of infection with early tube feeding may have passed. Based on the trial by Bakker et al. [11], it is now right to state that current evidence does not support an early start of nasoenteric tube feeding in all patients with severe AP in order to reduce the risks of infection and death [14].

\section{ERCP in Biliary Pancreatitis}

In a majority of cases, $\mathrm{AP}$ is initiated by the obstruction of gallstones at the level of the ampulla of Vater $[36,37]$. Entrapment of biliary stones or sludge is believed not only to initiate an attack of pancreatitis but also to sustain and possibly aggravate the disease. This is the reason why (early) biliary decompression by means of ERC with sphincterotomy was proposed as a means to ameliorate the disease course $[38,39]$. The presumed benefits of such 
intervention have to be weighed against potential complications that are associated with ERC and sphincterotomy such as pancreatitis, bleeding and perforation [40, 41].

Several studies on the indication and outcome of ERC in in patients with biliary pancreatitis have been published [42]. Guidelines declare that here is an undisputed indication for ERC in patients with concomitant cholangitis $[2,36]$. In patients with a predicted mild disease course, early ERC is not indicated, as in these patients the risk for complications does not outweigh the potential benefit. For patients with pancreatitis with concomitant cholestasis, guidelines suggest that ERC with sphincterotomy be performed, but the quality of evidence for this recommendation is moderate at best. In patients with a biliary pancreatitis with a predicted severe disease course but without concomitant cholangitis, data are conflicting. A meta-analysis did not show a beneficial effect of routine early ERC compared to conservative treatment [42]. Unfortunately, each of the included studies has notable shortcomings that prevent us from drawing a reliable conclusion from the aggregated data, in particular for patients with predicted severe biliary pancreatitis but without cholangitis [43]. For one, patients with a low pre-likelihood of a biliary etiology were included, as well as patients at low risk for developing complications, and patients with cholangitis at presentation. Second, patient selection criteria and study endpoints varied considerably between studies. Third, patients with and without cholestasis are not presented separately, and this precludes doing an important subgroup analysis. Fourth, routine 'early' ERC was not performed within $24 \mathrm{~h}$ after hospital admission but after $48-72 \mathrm{~h}$, and this may be too late to prevent complications from severe disease or increase the risk for ERC related complications. Fifth, study protocols did not specify if and when sphincterotomy should be performed. This resulted in many patients who underwent ERC without sphincterotomy. It is our opinion that sphincterotomy should be performed routinely in order to decompress the biliary duct, even in the absence of visible gallstones or sludge during ERC [44-46]. Sixth, no criteria were set to guarantee that ERCs were performed by experienced endoscopists, although ERC is an intervention that requires considerable training and expertise $[47,48]$. Finally, even if the data of all randomized trials are pooled, such analysis still has insufficient power to detect statistically significant effects of early ERC with sphincterotomy in patients with severe biliary pancreatitis without concomitant cholangitis with respect to major complications or death $[42,49]$. The Dutch Pancreatitis Study Group is currently conducting a multicenter randomized study in 232 patients to investigate whether early ERC with sphincterotomy compared to conservative treatment improves outcome in patients with biliary pancreatitis that are at high risk for complications but do not have cholangitis. Patient inclusion is already more than halfway and results are awaited in 2017.

\section{Disclosure Statement}

M.J.B. was a consultant and lecturer to Boston Scientific and Cook Medical and consultant to SOCAR and Uniqure.

\section{References}

$>1$ Peery, et al: Burden of gastrointestinal disease in the United States: 2012 update. Gastroenterology 2012;143:1179-1187.

-2 Working Group IAP/APA Acute Pancreatitis Guidelines: IAP/APA evidence-based guidelines for the management of acute pancreatitis. Pancreatology 2013;13(4 suppl 2):e1-e15.

-3 van Santvoort HC, Bakker OJ, Bollen TL, et al; Dutch Pancreatitis Study Group: A conservative and minimally invasive approach to necrotizing pancreatitis improves outcome. Gastroenterology 2011;141:1254-1263.

-4 Rodriguez JR, Razo AO, Targarona J, et al: Debridement and closed packing for sterile or infected necrotizing pancreatitis: insights into indications and outcomes in 167 patients. Ann Surg 2008;247:294-299.

5 Besselink MG, van Santvoort HC, Buskens E, et al: Probiotic prophylaxis in predicted se- vere acute pancreatitis: a randomised, doubleblind, placebo-controlled trial. Lancet 2008; 371:651-659.

6 Raraty MG, Halloran CM, Dodd S, et al: Minimal access retroperitoneal pancreatic necrosectomy: improvement in morbidity and mortality with a less invasive approach. Ann Surg 2010;251:787-793.

7 Fernández-del Castillo C, Rattner DW, Makary MA, et al: Débridement and closed packing for the treatment of necrotizing pancreatitis. Ann Surg 1998;228:676-684.

-8 Besselink MG, Verwer TJ, Schoenmaeckers EJ, et al: Timing of surgical intervention in necrotizing pancreatitis. Arch Surg 2007;142: 1194-1201.

-9 van Santvoort HC, Besselink MG, Bakker OJ, et al: Dutch Pancreatitis Study Group: A stepup approach or open necrosectomy for necro- tizing pancreatitis. N Engl J Med 2010;362: 1491-1502.

10 Seewald S, Groth S, Omar S, et al: Aggressive endoscopic therapy for pancreatic necrosis and pancreatic abscess: a new safe and effective treatment algorithm (videos). Gastrointest Endosc 2005;62:92-100.

-11 Bakker OJ, van Santvoort HC, van Brunschot S, et al; Dutch Pancreatitis Study Group: Endoscopic transgastric vs surgical necrosectomy for infected necrotizing pancreatitis: a randomized trial. JAMA 2012;307:10531061.

12 van Grinsven J, van Brunschot S, Bakker OJ, et al; Dutch Pancreatitis Study Group: Diagnostic strategy and timing of intervention in infected necrotizing pancreatitis: an international expert survey and case vignette study. HPB (Oxford) 2015, Epub ahead of print. 
13 van Baal MC, van Santvoort HC, Bollen TL, et al: Systematic review of percutaneous catheter drainage as primary treatment for necrotizing pancreatitis. Br J Surg 2011;98:18-27.

14 van Baal MC, Bollen TL, Bakker OJ, et al: The role of routine fine-needle aspiration in the diagnosis of infected necrotizing pancreatitis. Surgery 2014; 155:442-448.

$\checkmark 15$ Ammori BJ, Leeder PC, King RF, et al: Early increase in intestinal permeability in patients with severe acute pancreatitis: correlation with endotoxemia, organ failure, and mortality. J Gastrointest Surg 1999;3:252-262.

- 16 Besselink MG, van Santvoort HC, Renooij W, et al: Intestinal barrier dysfunction in a randomized trial of a specific probiotic composition in acute pancreatitis. Ann Surg 2009;250: 712-719.

17 Fritz S, Hackert T, Hartwig W, et al: Bacterial translocation and infected pancreatic necrosis in acute necrotizing pancreatitis derives from small bowel rather than from colon. Am J Surg 2010;200:111-117.

-18 Rahman SH, Ammori BJ, Holmfield J, Larvin M, McMahon MJ: Intestinal hypoperfusion contributes to gut barrier failure in severe acute pancreatitis. J Gastrointest Surg 2003;7: 26-35; discussion 35-36.

19 van Felius ID, Akkermans LM, Bosscha K, et al: Interdigestive small bowel motility and duodenal bacterial overgrowth in experimental acute pancreatitis. Neurogastroenterol Motil 2003; 15:267-276.

20 Marik PE: What is the best way to feed patients with pancreatitis? Curr Opin Crit Care 2009; 15:131-138.

21 McClave SA, Heyland DK: The physiologic response and associated clinical benefits from provision of early enteral nutrition. Nutr Clin Pract 2009;24:305-315.

22 Al-Omran M, Albalawi ZH, Tashkandi MF, Al-Ansary LA: Enteral versus parenteral nutrition for acute pancreatitis. Cochrane Database Syst Rev 2010;1:CD002837.

23 Marik PE, Zaloga GP: Early enteral nutrition in acutely ill patients: a systematic review. Crit Care Med 2001;29:2264-2270; erratum in Crit Care Med 2002;30:725.

24 Li JY, Yu T, Chen GC, et al: Enteral nutrition within 48 hours of admission improves clinical outcomes of acute pancreatitis by reducing complications: a meta-analysis. PLoS One 2013;8:e64926.

25 Petrov MS, Pylypchuk RD, Uchugina AF: A systematic review on the timing of artificial nutrition in acute pancreatitis. Br J Nutr 2009; 101:787-793.
6 Sun JK, Mu XW, Li WQ, Tong ZH, Li J, Zheng SY: Effects of early enteral nutrition on immune function of severe acute pancreatitis patients. World J Gastroenterol 2013;19:917922.

27 Wereszczynska-Siemiatkowska U, Swidnicka-Siergiejko A, Siemiatkowski A, Dabrowski A: Early enteral nutrition is superior to delayed enteral nutrition for the prevention of infected necrosis and mortality in acute pancreatitis. Pancreas 2013;42:640-646.

28 Bakker OJ, van Brunschot S, van Santvoort $\mathrm{HC}$, et al: Early versus on-demand nasoenteric tube feeding in acute pancreatitis. N Engl J Med 2014;371:1983-1993.

29 Kreymann KG, Berger MM, Deutz NE, et al: ESPEN guidelines on enteral nutrition: intensive care. Clin Nutr 2006;25:210-223.

30 Heyland DK, Dhaliwal R, Drover JW, Gramlich L, Dodek P; Canadian Critical Care Clinical Practice Guidelines Committee: Canadian clinical practice guidelines for nutrition support in mechanically ventilated, critically ill adult patients. JPEN J Parenter Enteral Nutr 2003;27:355-373.

31 Koretz RL, Lipman TO: The presence and effect of bias in trials of early enteral nutrition in critical care. Clin Nutr 2014;33:240-245.

32 McClave SA, Martindale RG, Vanek VW, et al: Guidelines for the provision and assessment of nutrition support therapy in the adult critically ill patient: Society of Critical Care Medicine (SCCM) and American Society for Parenteral and Enteral Nutrition (A.S.P.E.N.). JPEN J Parenter Enteral Nutr 2009;33:277316.

33 Meier R, Ockenga J, Pertkiewicz M, et al; DGEM (German Society for Nutritional Medicine), Löser C, Keim V; ESPEN (European Society for Parenteral and Enteral Nutrition): ESPEN guidelines on enteral nutrition: pancreas. Clin Nutr 2006;25:275-284.

34 Mirtallo JM, Forbes A, McClave SA, Jensen GL, Waitzberg DL, Davies AR; International Consensus Guideline Committee Pancreatitis Task Force: International consensus guidelines for nutrition therapy in pancreatitis. JPEN J Parenter Enteral Nutr 2012;36:284291.

35 Working Group IAP/APA Acute Pancreatitis Guidelines: IAP/APA evidence-based guidelines for the management of acute pancreatitis. Pancreatology 2013;13(4 suppl 2):e1-e15.

36 Tenner S, Baillie J, DeWitt J, Vege SS; American College of Gastroenterology: American college of gastroenterology guideline: management of acute pancreatitis. Am J Gastroenterol 2013;108:1400-1415, 1416.
37 Yadav D, Lowenfels AB: Trends in the epidemiology of the first attack of acute pancreatitis: a systematic review. Pancreas 2006;33: 323-330.

38 Opie EL: The aetiology of acute haemorrhagic pancreatitis. Bull Johns Hop Hosp 1901;xii: 182-188.

39 Lerch MM, Saluja AK, Runzi M, et al: Pancreatic duct obstruction triggers acute necrotizing pancreatitis in the opossum. Gastroenterology 1993;104:853-861.

40 Andriulli A, Loperfido S, Napolitano G, et al: Incidence rates of post-ERCP complications: a systematic survey of prospective studies. Am J Gastroenterol 2007;102:1781-1788.

-41 Freeman ML, Nelson DB, Sherman S, et al: Complications of endoscopic biliary sphincterotomy. N Engl J Med 1996;335:909-918.

42 Tse F, Yuan Y: Early routine endoscopic retrograde cholangiopancreatography strategy versus early conservative management strategy in acute gallstone pancreatitis. Cochrane Database Syst Rev 2012;5:CD009779.

$\checkmark 43$ Schepers NJ, van Santvoort HC, Bruno MJ; Dutch Pancreatitis Study Group: ERCP for gallstone pancreatitis. N Engl J Med 2014;370: 1955.

44 van Santvoort HC, Besselink MG, de Vries AC, et al: Early endoscopic retrograde cholangiopancreatography in predicted severe acute biliary pancreatitis: a prospective multicenter study. Ann Surg 2009;250:68-75.

45 Neoptolemos JP, Stonelake P, Radley S: Endoscopic sphincterotomy for acute pancreatitis. Hepatogastroenterology 1993;40:550-555.

46 Venneman NG, Renooij W, Rehfeld JF, et al: Small gallstones, preserved gallbladder motility, and fast crystallization are associated with pancreatitis. Hepatology 2005;41:738-746.

-47 Adler DG, Baron TH, Davila RE, et al; Standards of Practice Committee of American Society for Gastrointestinal Endoscopy: ASGE guideline: the role of ERCP in diseases of the biliary tract and the pancreas. Gastrointest Endosc 2005;62:1-8.

48 Baron TH, Petersen BT, Mergener K, Chak A, Cohen J, Deal SE, et al; ASGE/ACG Taskforce on Quality in Endoscopy: Quality indicators for endoscopic retrograde cholangiopancreatography. Am J Gastroenterol 2006;101:892897.

49 Petrov MS, van Santvoort HC, Besselink MG, et al: Early endoscopic retrograde cholangiopancreatography versus conservative management in acute biliary pancreatitis without cholangitis: a meta-analysis of randomized trials. Ann Surg 2008;247:250-257. 